\title{
Improvement of OSH Management through the holistic approach of incident controlling
}

\author{
Kristina Schreyer ${ }^{1, *}$, Arman Dehghani ${ }^{2}$, and Eleonora Fendeková ${ }^{2}$ \\ ${ }^{1}$ IU, Faculty of Business Management, Berg-am-Laim-Str. 47, 81672 MÜNCHEN, Germany \\ ${ }^{2}$ EUBA, Faculty of Business Management, Dolnozemská cesta 1/b, 85235 Bratislava, Slovak \\ Republic
}

\begin{abstract}
This paper deals with the performance optimization of occupational safety and health management (OSHM) with the help of the integration of near miss management into existing KPIs of the company. In this context, two independent processes are carried out: risk assessment and near miss management. In this work, the holistic view of these two processes is investigated as an optimization potential OSHM. Based on a literature review, the framework of the qualitative method applied here is established. After definitions and general information concerning OSHM, the processes of risk assessment and near miss management in different organisations (23 international plants for risk assessment and 6 German plants for near miss management) with established processes according to BPM are examined. The chosen approach is combined with the method of the PDCA cycle to relate the results of the investigation to the CIP existing in the OSHM. The result was elaborated in the form of a recommendation for action: optimization of existing processes, integrated hazard and near miss management as a more sustainable solution and proposal for the implementation of a KPI for better control of incidents based on predictive risk assessment.
\end{abstract}

\section{Introduction}

In management and steering of organization the performance indicators are important as key figures for measuring team performance in a process which demonstrate employees' ability by comparing it to their previous performance or the average level of industry and the growth potentials. The optimization of key figures in the field of human resource management is one of the companies' main objectives. Despite the significant role played by occupational safety and health management (OSHM) in this field, it is almost impossible to measure $\mathrm{OSH}$ using quantitative and especially prospective key figures. $\mathrm{OSH}$ is mostly considered an extra expense and thus a source of costs as well. This is mostly because it is scarcely possible to observe the practical advantage of workplace safety policies directly and instantly. Decreasing the resultant simplified vision is an important task in OSHM. [1] In a study, the German Social Accident Insurance (DGUV) proves the benefit of OSH for a company based on Return on Prevention (ROP).[2]

\footnotetext{
${ }^{*}$ Corresponding author: elenora.fendekova@euba.sk
} 
The legal and normative framework obligates the enterprises to determine and control the hazards and potential dangers at the workplace at an early stage. [3,4] Over the past decades, these regulations have enabled the EU to achieve a significant reduction in accidents and an increase in preventive OSH, which is to be further improved.[5] According to a survey conducted in 2015, 54 percent of German companies carry out a risk assessment.[6] This component of OSH is stated to be a competitive factor, as the costs of possible occupational accidents are avoided through appropriate OSH measures.[7] In addition, near misses could also contribute to improving the global effectiveness of an OSHM. A near miss can be defined as a dangerous situation and/or an unsafe act in which the chain of events could have resulted in an accident if it had not been broken. [8]

Accidents and near misses are usually characterized by common causes. In addition, near misses are a more relevant source of information for increasing the level of safety in an organization because they indicate deficiencies in safety systems, the so-called "weak signals" without causing high consequences. [9] Despite the similarity of accidents and near misses, they are recorded and monitored independently of each other. One of the reasons could be the lack of a legal requirement to record and control near misses. This work aims to develop a recommended approach for optimizing the OSHMS based on the integration of near misses into the risk assessment process, which is to be monitored by a suitable KPI.

\section{Theoretical Background / Literature review}

\subsection{OSHMS and modern risk assessment}

The positive effects of implementing occupational safety and health management systems (OSHMS) at organizational level, both in the reduction of hazards and risks and in productivity, is now widely recognized by governments, employers, and workers. [10] The entrepreneurial duties which are derived from the legal conditions are correspondingly complex and relate to both the normative, strategic and operative management level.[11] Employers are thus obliged, to carry out risk assessments of workplaces, define responsibilities in occupational safety, inform and train employees, monitor compliance with occupational safety regulations, etc. In order to be able to carry out these tasks in a systematic and formalized manner, the implementation of an operational OSHM is essential.[10] At the same time, the introduction of an OSHMS means that support from the top management and the consideration of $\mathrm{OSH}$ requirements in all processes of an organization secured. [12]

OSHM is the targeted and systematic planning, implementation, and monitoring of OSH as a management task. OSHM is above all a strategy and methodology for the systematic planning, organization, operation, and monitoring of OSH. It does not contain any claims beyond the valid public law obligations.[12] The model of modern OSH is based on a holistic understanding of safety and health at work, emphasizes the personal responsibility of an organization, its managers and employees, emphasizes the management task of "occupational safety and health", involves managers more closely in OSH and relies on regular evaluation with the aim of continuous improvement, integrates occupational safety into the operational processes and regards it as a process.[1] In detail, modern OSH comprises the following elements shown in Figure1:[1] 


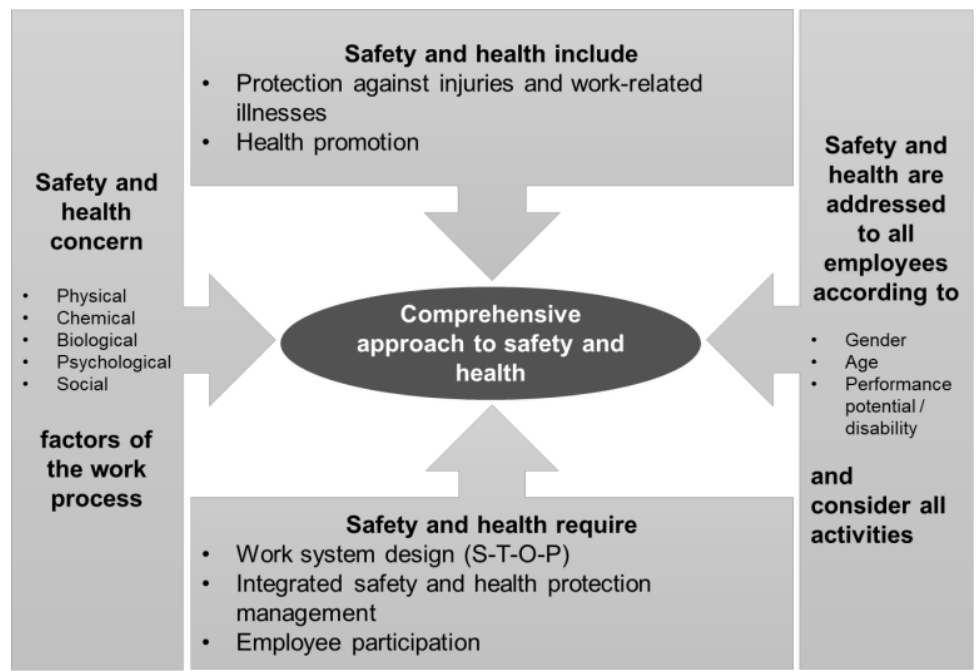

Fig. 1. Main elements of the OSH management system, own Illustration based on [1]

\subsection{Risk assessment}

Risk assessment is one of the most important steps in ensuring safety and health at work. [13] It is defined as the "systematic identification and evaluation of hazards". [1] This can be carried out both retrospectively and prospectively. Schlick et al. emphasize the prioritization of preventive OSH because of its predictive risk evaluation for the avoidance of accidents or potential hazards. [14] Risk assessment in accordance with the legal requirements (e.g. German OSH Act) is a concept for action to improve safety and health.

The central operational preventive instrument for this is the general overview of the working conditions to be created for the overall operation and action to be derived from it. So, the improvement of working conditions will be steered focused on the key priorities steered. The target management for overall company action can be justified in this way and effectively controlled. [1] The methodical approach for the assessment of working conditions according to $\S \S 5$ and 6 German Occupational Safety and Health Act is shown in Figure 2 .

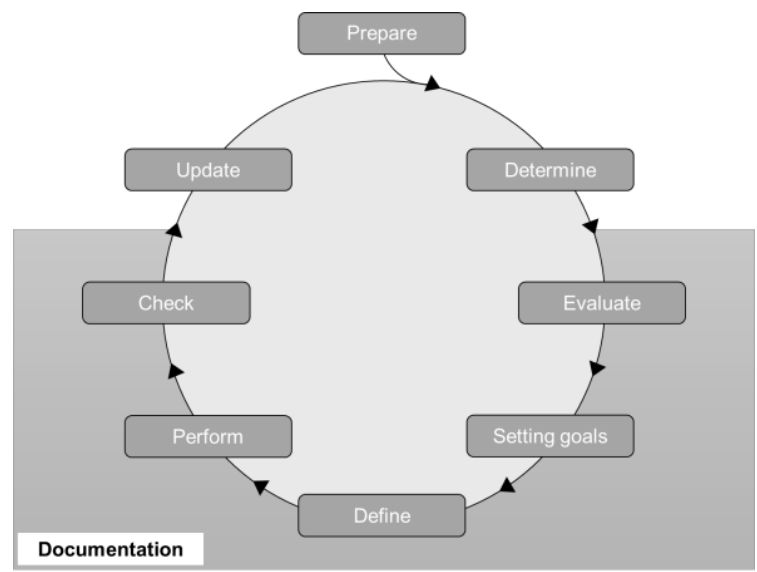

Figure Chyba! Dokument neobsahuje žiadny text so zadaným štýlom.. Methodical approach for risk assessment, own illustration based on [1] 


\subsection{Near miss}

A near miss is the result of a dangerous event at work that does not result in an injury to the employee, i.e., it is not an accident. [15] Nesmith, Keating, and Zacharias clarify that this presents an opportunity to gain valuable information to prevent future accidents.[16] This is visualized by the so-called accident pyramid and shown in Figure 3. Near misses form the basis of the accident pyramid. The time of a lost workday is considered a criterion of accident severity and thus an event occurs less frequently the more severe the accident is. [17]

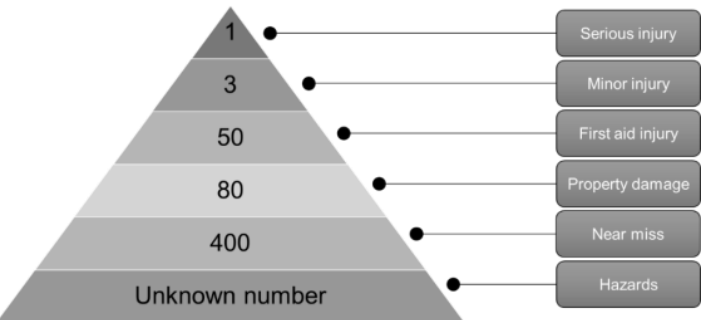

Figure 3. Accident Pyramid own illustration based on $[17,18]$

\section{Methodology}

The aim of the work is to develop a recommendation for optimizing the OSHM by means of integrating near misses into the risk assessment process. The basis for the recommended approach is the following research questions $(\mathrm{Q})$ :

Q1) How can the prevention process of OSHM be optimized through near miss management?

Q2) Which key figure(s) can make this optimized process sustained?

The following theses $(\mathrm{T})$ result from the research questions:

T1) By taking a holistic view of hazards and integrating near misses into the hazard assessment process, the OSHM prevention process will be optimized.

T2) The numerical risk assessment available in OSHM serve as a suitable key figure for this new holistic approach.

To achieve answers to the set objectives and research questions, the framework of the work is first established based on a literature review. The basis of the proposed recommendation is the process analysis of the risk assessment and the near miss reporting of selected sites. Within the framework of this investigation it comes to the application of the qualitative method of BPM in combination with PDCA-Cycle. The method selection was based on criteria of familiarity and applicability in relation to similar procedures of working in OSHM. The contents of the cyclical methodology correspond to both the PDCA cycle and the intended CIP. The proposed approach requires a qualitative analysis of the existing processes as well as the inclusion of quantitative measurability for the follow-up of the targeted process optimization. The existing sub-processes in OSHM are similar to this approach. This also speaks for the use of the methods mentioned.

The first phase is the process survey and includes the exact delineation of already existing processes from one another. The findings from this are summarized in the process documentation to form an as-is process model. Based on the as-is documentation, existing weaknesses can be identified as part of the process analysis. The causes determined from this serve as input for a renewed process conception, which results in a desired process model. This is followed by the process implementation of the desired model. Here, the 
necessary changes are implemented in the new as-is process. Continuous monitoring of the processes should be a continuous task, even if process controlling is mapped as the last step in this cycle. To analyse the presented current process, a qualitative method is used, as mentioned earlier. To uncover possible sources of waste of underutilized resources, a nonvalue-added analysis is applied, with the aim of making the process content more effective, as recommended by Dumas et al. [19] As noted, the chosen approach is combined with the quantitative method of the PDCA cycle. The data collection was carried out in 23 international sites to analyse the risk assessment process and 6 German sites for near miss management, all with the same production and similar structure and working culture.

\section{Results}

The analysis of risk assessment process shows that active updating is insufficiently integrated into the process and must therefore be regarded as a process gap. The result of the investigation on risk assessment process in 23 entities can be presented as Figure 4 . The weakness thus lies in the fact that prospective findings are not proactively considered, and no consequent implementation of countermeasures are taken to improve safety based on the investigation of near misses. The first two steps of the PDCA cycle, planning and execution, are considered, but not all the events required by the risk assessment guidelines are included in the third step of review. Thus, the cyclical approach is incomplete. This type of waste shows that the existing potential of the relevant safety instructions is not sufficiently exhausted and is disregarded as a link in the process chain. The possible adversary to the found process weakness is consequently the inclusion of near misses or recognized potential hazards in the risk assessment process. More specifically, the output of a near miss must serve as a renewed input to the CIP of the risk assessment. This change is visualized as a target model in Figure 5.
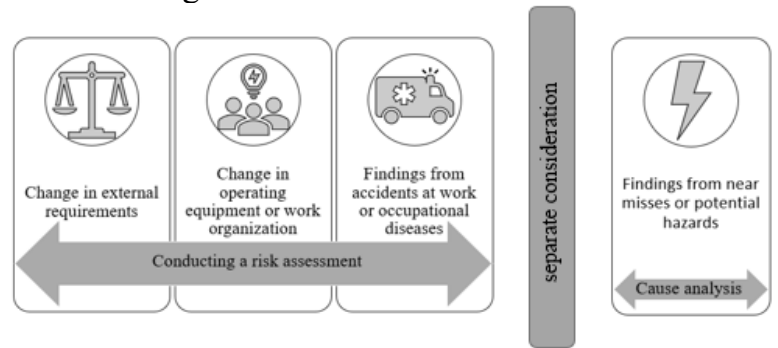

Figure 4. separate consideration of risk assessment and near miss management, own illustration

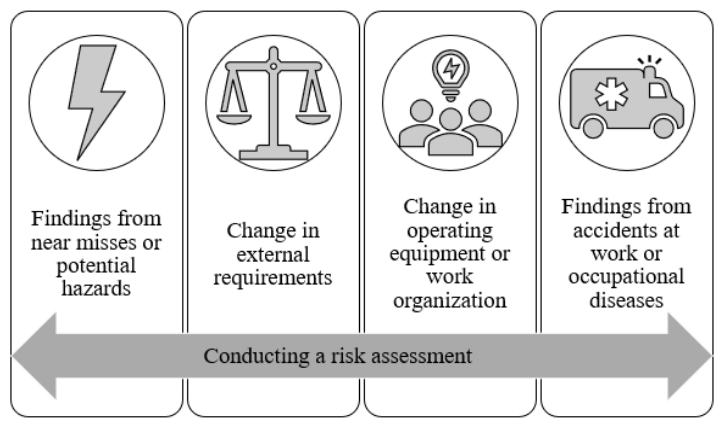

Figure 5. holistic risk assessment taking considering near miss management, own illustration

Proactive analysis and handling of near misses enables the inclusion of potential safety information and thus promotes safety and health protection of employees. The analysis of 
near miss management of 6 plants shows two common process weaknesses in all cases. First, the lack of reference to the overall accident analysis. The comprehensive analysis of all accidents enables direct reference to accident causes and insufficient measures to be taken in relation to each other. The second weakness can be defined as a missing indicator for the evaluation of occupational safety regarding incidents.

The integrated linking of incidents to each other supports the occupational safety of employees and promotes the prospective prevention of near misses. When similar incidents are repeated, it is an indicator that a more thorough investigation and analysis is needed to eliminate the cause of a potential accident. [17] Accordingly, it enables the assessment of the effectiveness and quality of the safety level and the countermeasures that have already been implemented. The additional use of key performance indicators, besides the reasons of performance evaluation, can also serve as an instrument for early warning. In the context of the present work, this is a very great benefit for the company.

It is recommended to include the risk matrix according to "Nohl", which is already used for risk assessment, in the processing of near misses. In most cases, the recognized hazard potential is classified as having a low impact and an unlikely frequency of occurrence, but a subsequent event can lead to an increase in these criteria. [20] Figure 6 visualize this relation.

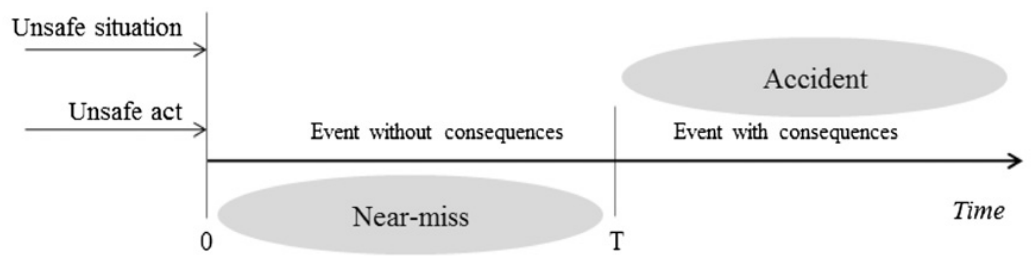

Figure 6. relation between near miss and accident.[9]

An early warning instrument of this kind can measurably highlight changes and anomalies. Thus, early forecasts are possible and negative developments can be interrupted by appropriate countermeasures. [20] The integration of an early warning indicator can be based on the Predictive Risk Index (PRI) according to Chen \& Yang to predict an accident. [15] With the help of the PRI, the occurrence of an event can be predicted in that, for example, an increasing trend indicates a greater probability of a future accident. The existing system can be extended to include the PRI with little effort.

\section{Discussion and Conclusion}

The main component of the investigation result is the existing process gap and the missing reference to key figures. These factors are significantly decisive for the continuous improvement and effectiveness of the OSHM. The system-based implementation of a dependent consideration of all incidents is associated with little effort using IT tools. The integration of the PRI represents a further interesting optimization. It has been explained why an early warning indicator is an important instrument in the context of the reference to key figures. The core of the advantage over other possible indicators is the explicit promoting of preventive occupational safety, which makes such a PRI indispensable. The integration of a PRI into the organizations' KPI system is also rated as low cost.

Furthermore, the essential criteria for optimizing the OSHM were identified and executed during the process analyses. A number of recommendations for action emerge from the comparison of these results with the practice of existing systems:

- Integration of near misses into the event-related review of risk assessments.

- Comprehensive analysis of causes and measures for all reportable incidents. 
- Concept development and integration of key figures for optimized measurability of accident occurrence, exemplified by a PRI.

Since this is a study of comparable companies with similar structures and production, it must be considered that a scattering of the company structure and/or culture can partially influence the results.

In $\mathrm{OSH}$, the control of complete process chains by means of key figures offers great potential for reducing company costs and for preventive support of employee safety and health. The digital transformation taking place in the context of Industry 4.0 enables the collection of ever greater volumes of data and thus the opportunity to improve the performance of existing control instruments. Preventive action on potential hazards is indispensable for the continuous improvement of the OSHM.

Acknowledgment: The authors would like to thank the participating contact persons of the respective plants and for the information provided.

\section{References}

1. Bundesanstalt für Arbeitsschutz und Arbeitsmedizin (BAuA). (Hrsg). Indikatoren und Parameter zur Bewertung der Qualität des Arbeitsschutzes im Hinblick auf Arbeitsschutzmanagementsysteme. German federal institute for OSH, 959, 177 (2002). View. 21.01.2021.

https://www.baua.de/DE/Angebote/Publikationen/Schriftenreihe/Forschungsberichte/2 220/Fb959.pdf?__blob=publicationFile

2. D. Bräunig, T. Kohlstall, Berechnung des internationalen "Return on Prevention" für Unternehmen: Kosten und Nutzen von Investitionen in den betrieblichen Arbeits- und Gesundheitsschutz. Deutsche Gesetzliche Unfallversicherung DGUV Report 1 (2013)

3. German OSH Act, Gesetz über die Durchführung von Maßnahmen des Arbeitsschutzes zur Verbesserung der Sicherheit und des Gesundheitsschutzes der Beschäftigten bei der Arbeit (Arbeitsschutzgesetz - ArbSchG). Arbeitsschutzgesetz vom 7. August 1996 (BGBl. I S. 1246), das zuletzt durch Artikel 427 der Verordnung vom 31. August 2015 (BGB1. I S. 1474) geändert worden ist. [Online]. https://www.gesetze-iminternet.de/arbschg/ArbSchG.pdf

4. DIN ISO 45001, Occupational health and safety management systems - Requirements with guidance for use (ISO 45001 :2018), 2018

5. EU-Kommission, Mitteilung der Kommission an das Europäische Parlament, den Rat, den Europäischen Wirtschafts- und Sozialausschuss und den Ausschuss der Regionen über einen strategischen Rahmen der EU für Gesundheit und Sicherheit am Arbeitsplatz, www.ec.europa.eu/social/main.jsp?catId=151\&langId=de, 4-5, 2014

6. Bundesministerium für Arbeit und Soziales (BMAS), Sicherheit und Gesundheit bei der Arbeit - Berichtsjahr 2017 : Unfallverhütungsbericht Arbeit, view : 3.03 .2021 von www.baua.de/dok/8809570, 28, 2018

7. M., Kittelmann, L., et al., Handbuch Gefährdungsbeurteilung : Teil 1 Grundlagen und Prozessschritte der Gefährdungsbeurteilung, BAUA,6, 2021 https://www.baua.de/DE/Angebote/Publikationen/Fachbuecher/Gefaehrdungsbeurteilu ng.pdf?_blob=publicationFile\&v=37 doi: 10.21934/baua:fachbuch20210127

8. S. Jones, C., Kirchsteiger, W., Bjerke, The importance of near-miss reporting to further improve safety performance. Journal of Loss Prevention in the Process Industries 12, 59-67(1999). 
9. M.G. Gnoni, G. Lettera, Near-miss management systems: A methodological comparison, Journal of Loss Prevention in the Process Industries 1, doi:10.1016/j.jlp.2012.01.005 (2012),

10. International Labour Organisation : Guidelines on occupational safety and health management systems - ILO-OSH 2001. Geneva : International Labour Office. (2009)

11. J. Brauweiler, A. Zenker-Hoffmann, Arbeitsschutzmanagementsysteme nach OHSAS 18001. Grundwissen für Praktiker. Wiesbaden : Springer Gabler, 1 (2014)

12. A., Ritter, Arbeitsschutzmanagementsysteme. In : Wörterbusch Arbeitssicherheit und Gesundheitsschutz, 9 Aufl. Wiesbaden : Universum Verlagsanstalt, 1 (2009)

13. K., Knöll, P. Lugbauer, Arbeitsschutz, Arbeitsmedizin und Gefährdungsbeurteilung Zukunftsorientierte Ausrichtung im Unternehmen. In Simmel, M. \& Graß1, W. (Hrsg.), Betriebliches Gesundheitsmanagement mit System, Wiesbaden : Springer Fachmedien Wiesbaden. doi : 10.1007/978-3-658-26956-2_6, 44 (2020)

14. C., Schlick, et al., Arbeitswissenschaft (4. Auflage). Berlin : Springer. Abgerufen von http://www.springer.com/, 394 (2018).

15. J., R., Chen, Y., T., Yang, A predictive risk index for safety performance in process industries, doi: 10.1016/j.jlp.2004.03.001, Journal of Loss Prevention in the Process Industries, 17, 233-242, (2004).

16. G., Nesmith, J., T., Keating, L., A., Zacharias, Investigating process safety near misses to improve performance. Process Safety Progress, doi: 10.1002/ prs. 11563 Ggg, 32, 170-171(2013)

17. F., W., Nerdinger, G., Blickle, N., Schaper, Arbeits- und Organisationspsychologie, Springer-Lehrbuch, 4., vollständig überarbeitete Auflage. Berlin, Germany : Springer. Abgerufen von http://www.springer.com/, 544 (2019)

18. J., Wallace, Developing Effective Safety Systems; IChemE, 1995; ISBN 0852953585

19. M. Dumas, et al., Fundamentals of business process management (Computer science, Second edition). Berlin, Germany : Springer. Abgerufen von http://www.springer.com/, 23 (2018)

20. H., U., Küpper, et al., Controlling: Konzeption, Aufgaben, Instrumente (6. Aufl.). s.l. : Schäffer-Poeschel Verlag. Abgerufen von http://site.ebrary.com/lib/alltitles/docDetail.action?docID=10773156, 478 (2013). 